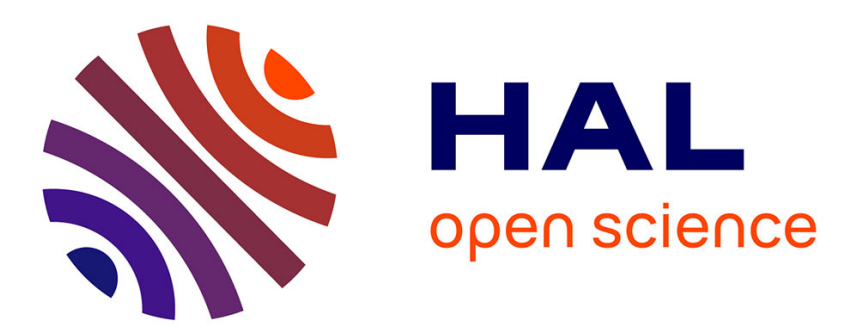

\title{
Impurity and Stoichiometry Effects in the Preparation and Mechanical Properties of Intermetallic NiAl Single Crystals
}

\author{
A. Köthe, W. Löser, A. Güth, G. Vaerst, K. Mai
}

\section{- To cite this version:}

A. Köthe, W. Löser, A. Güth, G. Vaerst, K. Mai. Impurity and Stoichiometry Effects in the Preparation and Mechanical Properties of Intermetallic NiAl Single Crystals. Journal de Physique IV Proceedings, 1995, 05 (C7), pp.C7-111-C7-122. 10.1051/jp4:1995709 . jpa-00254002

\section{HAL Id: jpa-00254002 https://hal.science/jpa-00254002}

Submitted on 1 Jan 1995

HAL is a multi-disciplinary open access archive for the deposit and dissemination of scientific research documents, whether they are published or not. The documents may come from teaching and research institutions in France or abroad, or from public or private research centers.
L'archive ouverte pluridisciplinaire HAL, est destinée au dépôt et à la diffusion de documents scientifiques de niveau recherche, publiés ou non, émanant des établissements d'enseignement et de recherche français ou étrangers, des laboratoires publics ou privés. 


\title{
Impurity and Stoichiometry Effects in the Preparation and Mechanical Properties of Intermetallic NiAl Single Crystals
}

\author{
A. Köthe, W. Löser, A. Güth, G. Vaerst and K. Mai \\ Institut für Festkörper und Werkstofforschung Dresden e. V./, Institut für metallische Werkstoffe, \\ Postfach 2700 16, 01171 Dresden, Germany
}

\begin{abstract}
NiAl single crystals with small deviation from stoichiometry and low impurity content were grown by a modified Bridgman technique. The starting material was melted in a vacuum induction furnace with a composition slightly hyper-stoichiometric in $\mathrm{Al}$. The adjustment of stoichiometry was effected by preferred $\mathrm{Al}$ evaporation during a preceding vacuum treatment of the melt in the Bridgman apparatus. Theoretical and experimental investigations of the $\mathrm{Ni}$ and $\mathrm{Al}$ distribution in the single crystals revealed macro-segregations with increasing concentration of the surplus element in the length direction as well as near the crystal surface. Crystals with low deviation from stoichiometry had a nearly constant composition over most of their length and significant macro-segregations only in the last-solidifying part, whereas crystals with larger deviations from stoichiometry showed a gradual increase in concentration of the surplus element with increasing slope as a function of the length co-ordinate. The macro-segregations caused corresponding variations of the microhardness HV0.05 in both the axial and radial directions. Room temperature compression tests of softoriented single crystals (sample axes in the $<111>-,<123>$ - and $<112>$-direction) exhibited values of yield strength and critical resolved shear stress comparable with those of high purity single crystals reported in the literature and ductilities of the order of $\geq 25 \%$.
\end{abstract}

\section{INTRODUCTION}

The intermetallic compound $\mathrm{NiAl}$ with cubic $\mathrm{B} 2$ structure is known to be a potential candidate material for high temperature structural applications offering a number of advantages in comparison with Ni-based super-alloys (high melting temperature, lower specific weight, good oxidation resistance, higher thermal conductivity). Up till now its application is, however, hampered by two essential shortcomings: insufficient ductility at room temperature, and low static and creep strength at high temperature.

With respect to room temperature ductility and toughness, several possible causes are being discussed in the literature which may contribute to the low values generally found (for a literature review see [1-3]):

- the small number of independent slip systems ( 3 of type $<001>\{110\}$ ),

- the embrittling effect of impurity atoms, especially of interstitial impurities (strain ageing),

resulting in a low density of mobile dislocations,

- low dislocation mobility due to a high Peierls potential,

- structural defects due to deviations from stoichiometric composition,

- quenched-in thermal vacancies (formed even by modest cooling rates due to a relatively low

formation energy and high migration energy of vacancies)

- voids caused by condensation of thermal vacancies,

- low cleavage fracture stress compared to yield stress.

Despite a large number of investigations on operative slip systems and deformation properties at room temperature, many details of the effects of deviations from stoichiometry and of impurities on room temperature ductility and thus the inherent properties of pure stoichiometric NiAl are still unclear. Often single crystals with quite large or unknown deviations from stoichiometry are used in the experiments published in the literature. Therefore, the present paper deals with investigations aimed at the improvement of purity and the reduction of deviations from stoichiometric composition of $\mathrm{NiAl}$ single crystals and their influence on room temperature ductility. 


\section{EXPERIMENTAL DETAILS}

\subsection{Crystal preparation}

Master alloys of different compositions within the range 45 to 55 at-\% Al were melted from $99.999 \%$ pure $\mathrm{Al}$ and $99.98 \%$ pure $\mathrm{Ni}$ in a vacuum induction furnace and cast in a copper mold. From this starting material NiAl single crystals of $12 \mathrm{~mm}$ diameter and about $100 \mathrm{~mm}$ length were grown in a Bridgman apparatus in alumina crucibles. The initial melt temperature was $1730^{\circ} \mathrm{C}$, the growth velocities ranged from 10 to $30 \mathrm{~mm} / \mathrm{h}$. The temperature gradient near the crystallization front was about $2.5 \mathrm{~K} / \mathrm{mm}$.

Additionally some crystals were prepared by containerless zone refining with induction heating in an $\mathrm{Ar}-\mathrm{H}_{2}$ atmosphere at a pressure of $9 \cdot 10^{4} \mathrm{~Pa}$ (this technique is still in the development phase).

The chemical composition of the crystals was analyzed by the following methods:

- main components / stoichiometry: chemically by a titration method,

- substitutional impurities: by spark source mass spectrography,

- oxygen and nitrogen: by carrier gas hot extraction,

- carbon and sulphur: by combustion.

A further check of stoichiometry was carried out by means of measurements of the reciprocal residual resistivity ratio R.R.R. $=\rho_{297 \mathrm{~K}} / \rho_{4.2 \mathrm{~K}}$ which shows a maximum at the stoichiometric composition.

The homogeneity of the crystals was studied by secondary ion mass spectrometry and by electron probe microanalysis line scans of $\mathrm{Ni}$ in the wavelength-dispersive mode in longitudinal and transversal direction on sections cut parallel to the crystal axis. These sections were cut with a diamond-coated wire saw, ground and polished with diamond paste. On the same sections microhardness measurements using a load of $50 \mathrm{p}$ (HV0.05) were carried out.

In order to prepare Bridgman single crystals with small deviation from stoichiometry a new melting technique was applied. Measurements of the vapour pressure above NiAl melts showed [4] that the partial pressure of $\mathrm{Al}$ is about two orders of magnitude higher than that of Ni. A theoretical model allows the estimation of the evaporation losses of $\mathrm{Al}$ and $\mathrm{Ni}$, respectively.

From these results it is possible, starting with a slightly Al-rich alloy composition, to adjust the chemical composition of the alloy by $\mathrm{Al}$ evaporation via a vacuum treatment of the melt under well defined conditions with respect to temperature, time, vacuum pressure, and geometry (mass of the melt and surface-to-volume ratio), see Fig. 1. This vacuum treatment is not carried out in the induction furnace when preparing the master alloy, but in the Bridgman apparatus before the crystallization process starts.

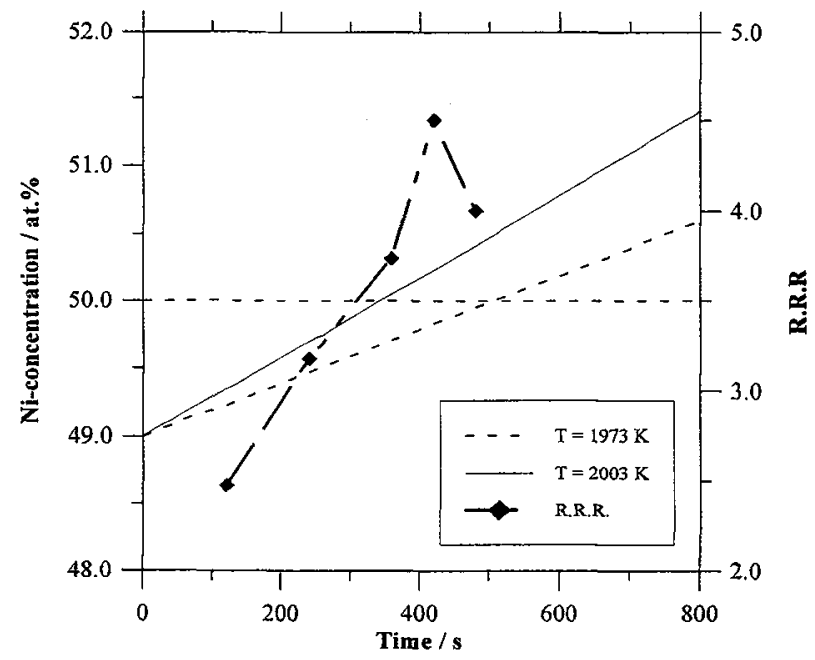

Figure 1: Calculated change of stoichiometry of $\mathrm{NiAl}$ single crystals as a result of a vacuum treatment of the melt within the Bridgman apparatus as a function of time and temper-ature, and reciprocal residual resistivity ratio R.R.R. of the crystals 
This method offers two main advantages:

1. After calibration of the evaporation rate of $\mathrm{Al}$, crystals with stoichiometric composition as well as with defined deviations from stoichiometry can be produced using appropriate parameters of initial Al surplus and duration and temperature of the vacuum treatment.

2. Selective evaporation of other impurities during this treatment improves the overall purity level of the crystals.

Starting with a master alloy of $\mathrm{Ni}-51$ at-\% $\mathrm{Al}$ and $\mathrm{Ni}-50.7$ at-\% $\mathrm{Al}$, respectively, the effect of the duration of the vacuum treatment at $10^{-2} \mathrm{~Pa}$ and a melt temperature of $1700 \ldots 1730^{\circ} \mathrm{C}$ is illustrated in Table 1 . According to [5-7] R.R.R. values $\geq 4$ correspond to deviations from stoichiometric composition of $\leq 0.1$ at-\% (in [6] the following values were measured: $\mathrm{Ni}-49.8$ at-\% Al : R.R.R. $=4.95 ; \mathrm{Ni}-50.3$ at-\% Al: R.R.R. =2.84). The crystals numbered F39, F41 and F43 showed a greyish tail edge surface indicating a slight surplus of $\mathrm{Al}$, whereas crystal F45 showed a yellow tail edge characteristic of a slightly Ni-rich composition. No colour variation was visible at the surface of crystal no. F44. The small decrease of R.R.R. of this crystal at the tail end is due to a slightly increased deviation from stoichiometry caused by segregation (see below).

Table 1: Influence of a vacuum treatment of $\mathrm{NiAl}$ melts at $1700-1730^{\circ} \mathrm{C}$ on the reciprocal residual resistivity ratio (R.R.R.) of Bridgman single crystals

\begin{tabular}{|l|c|c|c|}
\hline \multicolumn{1}{|c|}{ Crystal No. } & Master alloy & $\begin{array}{c}\text { Duration of vacuum } \\
\text { treatment / s }\end{array}$ & R. R. R. \\
\hline F39 & Ni - 51 at-\% Al & 120 & 2.48 \\
F41 & & 240 & 3.17 \\
F43 & & 360 & 3.74 \\
F44 (head) & & 420 & 4.5 \\
F44 (tail) & & 420 & 4.2 \\
F45 & & 480 & 4.0 \\
\hline F57 (head) & Ni - 50.7 at-\% Al & 240 & 3.95 \\
F57 (tail) & & 240 & 3.14 \\
F58 & & 270 & 3.7 \\
F59 & & 270 & 4.15 \\
\hline
\end{tabular}

Crystals of conventional purity contained about $20 \mathrm{wt}$-ppm of metallic impurities, $<50 \mathrm{wt}$.-ppm oxygen and $<5$ wt.-ppm nitrogen. The high purity crystals prepared here contained about 7 wt.-ppm oxygen and 2 wt.-ppm nitrogen. Compared with the literature, where crystals of nominal stoichiometric composition sometimes exhibit deviations from stoichiometry of the order of up to a few percents (see e.g. Table I in [5]), the method developed here offers improved possibilities of reproducible preparation of single crystals of well-defined composition.

\subsection{Substructure of the single crystals}

The substructure of the as-grown crystals was characterized by thin foil transmission electron microscopy with a JEOL $200 \mathrm{CX}$ electron microscope and by metallographic investigation of dislocation etch pits. Dislocation etch pits were produced by etching with $10 \%$ nitric acid at $37^{\circ} \mathrm{C}$ (see Fig. 2 for etch pits on a (112) plane). The single crystals had mean dislocation densities between $5 \cdot 10^{4}$ and $10^{6} \mathrm{~cm}^{-2}$.

\subsection{Compression tests}

The orientation determination of the single crystals and of the compression samples was carried out using the Laue back reflexion method. Compression samples $5 \times 5 \mathrm{~mm}$ in cross section and $8 . .10 \mathrm{~mm}$ in length were prepared by electrical discharge wire cutting followed by mechanical grinding and polishing and electrochemical polishing. Samples with axis orientations $\langle 111\rangle,\langle 112\rangle$ and $\langle 123\rangle$ ("soft orientations") were prepared. The compression tests were carried out at room temperature in Instron 8502 and 8562 
testing machines with a constant cross head velocity of $1.7 \cdot 10^{-3} \mathrm{~mm} / \mathrm{s}$ corresponding to an initial strain rate of $1.7 \ldots 2.1 \cdot 10^{-4} \mathrm{~s}^{-1}$. The tests were run until failure or discontinued for TEM investigations.

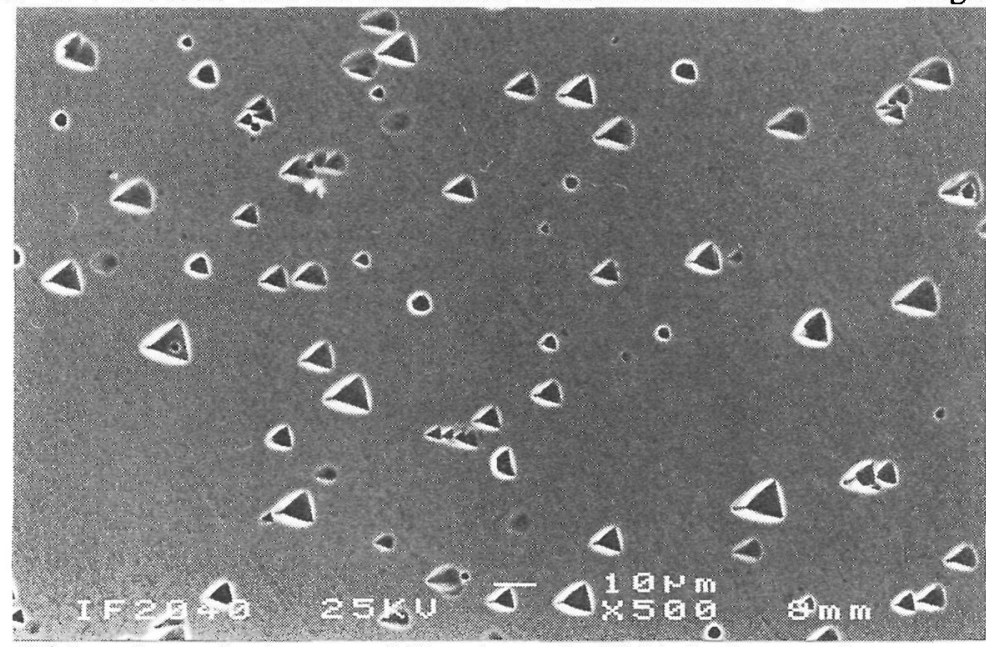

Figure 2: $\quad$ Dislocation etch pits on a $<112>$ plane of a NiAl single crystal

\section{RESULTS}

\subsection{Elemental distribution and homogeneity in binary NiAl single crystals}

Through elemental partition at the solid-liquid interface, the solidification process can introduce local deviations in the alloy composition and thus in the stoichiometry which can give rise to variations of the mechanical properties within a crystal. Therefore, the directional solidification process was analyzed with respect to elemental partitioning effects based on a solidification model with composition-dependent partition coefficients.

The isothermal concentration ratio of two phases at thermodynamic equilibrium is by definition characterized by the distribution coefficient

$$
\mathrm{k}=\frac{\mathrm{c}_{\mathrm{s}}}{\mathrm{c}_{1}}=\frac{\mathrm{X}_{\mathrm{c}}+\mathrm{x}_{\mathrm{s}}}{\mathrm{X}_{\mathrm{c}}+\mathrm{x}_{1}}
$$

where $X_{c}=50$ at $\%$ is the stoichiometric composition of the congruently melting intermetallic compound $\mathrm{NiAl}$, and $\mathrm{c}_{\mathrm{s}}$ and $\mathrm{c}_{1}$ are the solute concentrations of the solid and the melt, respectively. Therefore, the deviations from stoichiometric composition are characterized by $x_{s}=c_{s}-X_{c}$ and $x_{1}=c_{1}-X_{c}$.

The distribution coefficient has the value $k=1$ only at the exact stoichiometric composition $\left(x_{s}=x_{1}=0\right)$. Deviations from stoichiometric composition of the melt lead to macro-segregations in the crystal due to a shift of the elemental concentrations between solid and liquid phase. With the usual assumptions

$-\mathrm{k}=$ const.

- no concentration equilibration by diffusion in the solid phase

- concentration equilibration in the liquid phase

one obtains the well-known Scheil equation [9]

$$
c_{s}(g)=k \cdot c_{o}(1-g)^{(k-1)}
$$

( $g$ : fraction crystallized ; $\mathrm{c}_{\mathrm{o}}$ : initial concentration of the melt).

However, in the congruently melting intermetallic compound $\mathrm{NiAl}$ in case of deviations from stoichiometry the supposition $k=$ const is not fulfilled. Instead, a concentration-dependent distribution coefficient $k\left(c_{1}\right)$ has to be used, yielding the crystallized fraction $\mathrm{g}$ as a function of the solute concentration in the melt $\mathrm{c}_{1}$ as 


$$
g\left(c_{1}\right)=1-\exp \left\{\int_{c_{o}}^{c_{1}} \frac{d c_{1}}{\left[k\left(c_{1}\right)-1\right] \cdot c_{1}}\right\}
$$

For numerical evaluation, the liquidus and solidus curves $\mathrm{T}_{1}\left(\mathrm{x}_{1}\right)$ and $\mathrm{T}_{s}\left(\mathrm{x}_{\mathrm{s}}\right)$ of the $\mathrm{Ni}$-Al phase diagram near the melting point maximum $\mathrm{T}_{\mathrm{o}}=1638{ }^{\circ} \mathrm{C}$ on both sides of the stoichiometric composition $\mathrm{X}_{\mathrm{c}}=50$ at- $\%$ were approximated by biquadratic polynomials in the concentrations $\mathrm{x}_{1}$ and $\mathrm{x}_{\mathrm{s}}$. From the equilibrium condition $T_{s}\left(c_{s}\right)=T_{1}\left(c_{1}\right)$ the composition-dependent partition coefficient can be derived which is then used in the numerical integration of equ. (3) which yields the composition of the crystal as a function of the crystallized fraction, i. e. of the normalized length of the crystal z/L (L: total length of the crystal).

Fig. 3 shows the calculated $\mathrm{Ni}$ concentration along the crystal axis for three initial melt compositions (45 $49-51$ at-\% Al). Starting with Ni-rich melts the Ni concentration increases monotonically along the crystal axis, whereas in Al-rich crystals the Ni concentration decreases over the length of the crystal. For small deviations from stoichiometry of about $1 \%$ the composition is nearly constant over a large part of the length, and the concentration of the surplus element increases sharply only in the finally solidifying residual melt. This increase is, however, less sharp as compared to the results obtained with the Scheil equation (2) based on a constant $\mathrm{k}$. In crystals with larger deviations from the stoichiometric composition the increase in $\mathrm{Ni}$ concentration is seen from the beginning with increasing slope along the crystal axis.

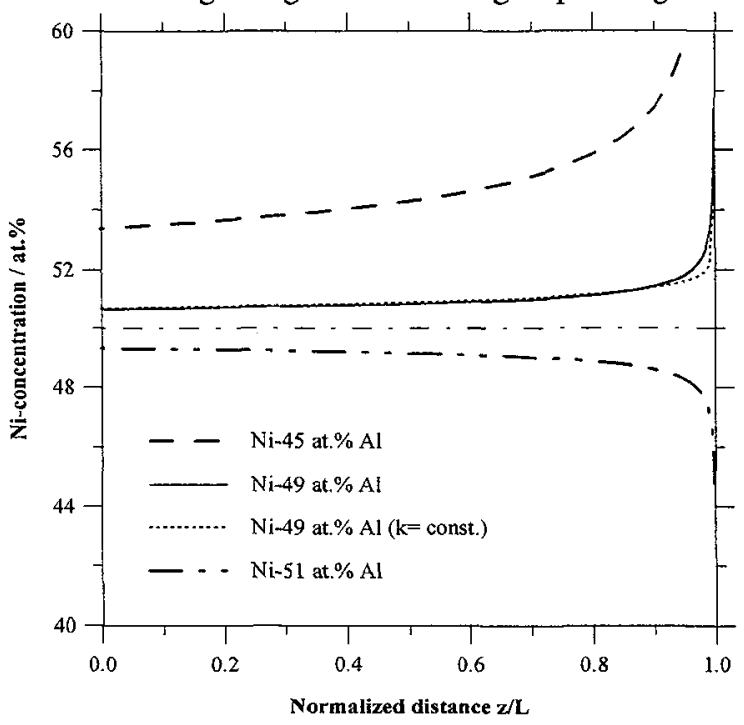

Figure 3: Ni concentration calculated with equation (3) as a function of the normalized length co-ordinate of Bridgman NiAl single crystals for 3 initial nominal melt compositions.

Dotted line: calculated using the Scheil equation (2) with $\mathrm{k}=$ const.

Experimental results obtained by electron probe microanalysis on crystals of nominal $\mathrm{Al}$ concentrations of 47.0, 48.8 and 51.6 at- $\%$ are presented in Fig. 4 . They principally confirm the theoretical calculations. Fig. 4 shows values measured along the crystal axis as well as those measured about $200 \mu \mathrm{m}$ below the surface. In crystals with small deviation from stoichiometry the differences between the centre and the region below the surface are negligible. They become more pronounced, however, if the deviation from overall stoichiometry increases (and thus are larger at the tail end of the crystals) exhibiting a greater increase of the concentration of the surplus element near the surface.

The increased concentration near the sample surface is due to a cellular flow pattern of the melt in the vertical Bridgman process. This melt flow is directed upwards near the hot crucible walls and, correspondingly, downwards in the centre [10]. It leads to a stagnant diffusion boundary layer at the solid/liquid interface causing an effective partition coefficient $\mathrm{k}<\mathrm{k}_{\mathrm{eff}}<1$. The thickness of this diffusion layer increases from centre to surface so that $k_{\text {eff }}$ will depend on the radial co-ordinates [11] leading to an increased accumulation of the surplus element ahead of the interface in the sub-surface region (for more details of the elemental partition in Bridgman-grown NiAl single crystals see [12,13]). 


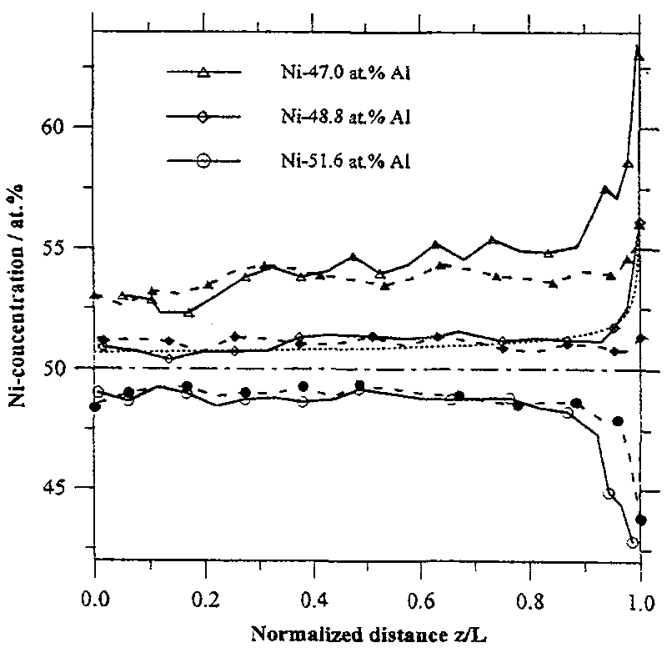

Figure 4: Experimentally determined $\mathrm{Ni}$ concentrations (electron probe microanalysis) as a function of the normalized length co-ordinate of Bridgman NiAl single crystals along the crystal axis (dashed lines, filled symbols) and about $\quad 200 \mu \mathrm{m}$ below the crystal surface (continuous lines, open symbols) for single crystals with different initial melt composition.

Dotted line: calculated by equation (3)

\subsection{Microhardness measurements}

The local stoichiometry deviations in $\mathrm{NiAl}$ single crystals discussed above may give rise to considerable variations in mechanical properties. Figs. 5 and 6 present results of microhardness measurements HV0.05.

Fig. 5 shows the hardness along the axis of crystals with $48.7,50.04$ and 51.6 at- $\%$ Al, respectively. The hardness remains relatively constant at a level of about $300 \mathrm{HV} 0.05$ for nearly stoichiometric compositions and for most of the length of the crystal but increases with increasing deviation from stoichiometry at the tail end of the crystal. In this region an Al surplus gives more pronounced effects than an excess of $\mathrm{Ni}$.

The radial variations of HV0.05 in a crystal of the basic composition $\mathrm{Ni}-47$ at $-\%$ Al for two positions with respect to the length co-ordinate are given in Fig. 6. The higher hardness near the sample surface as compared to the central region is obvious. Again the variation is much more pronounced in the lastsolidifying region $(z / L=0.99)$ in comparison to the main part of the crystal. Here the formation of a dendritic structure containing additional $\mathrm{Ni}_{x} \mathrm{Al}_{y}$ phases as discussed in [12] may contribute to the pronounced incre. ' $\mathrm{e}$ in hardness.

\subsection{Compression tests}

The mechanical behaviour of the NiAl single crystals was tested in uni-axial compression at room temperature. Three "soft" orientations with predicted $<001>\{110\}$ slip were selected: specimens with $<123>$ or $<112>$ axis direction are oriented for single slip, and specimens with $<111>$ axis are oriented for multiple slip on the three conjugated slip systems of the $<001>\{110\}$ type. The corresponding Schmid factors are summarized in Table 2.

Typical compressive stress-strain curves at room temperature for single crystals with axis orientation $<111\rangle,<123\rangle$ and $<112>$ are shown in Figs. $7-9$.

In Table 3 , the values of the $0.2 \%$ offset yield stress, the critical resolved shear stress and the work hardening rate of the crystals tested are summarized and compared with results of other authors. 


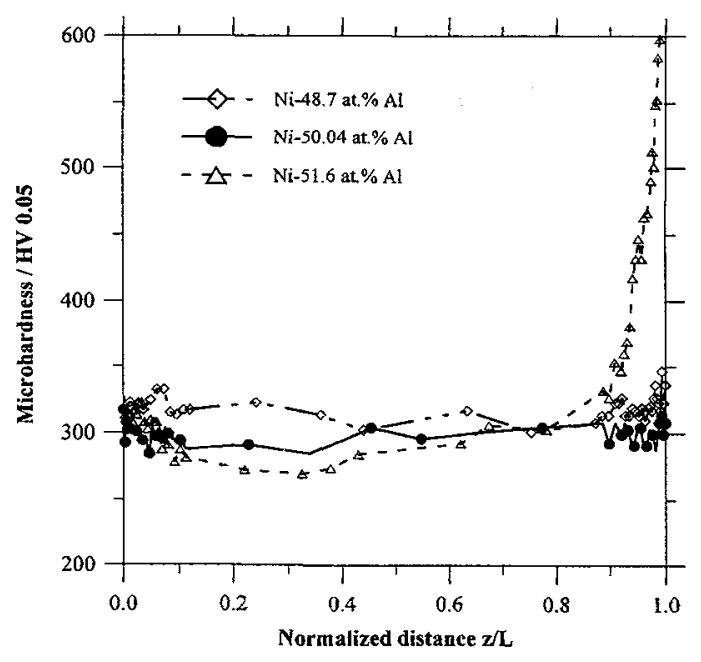

Figure 5: Microhardness HV0.05 as a function of the normalized length co-ordinate along the axis of Bridgman NiAl single crystals of different nominal composition.

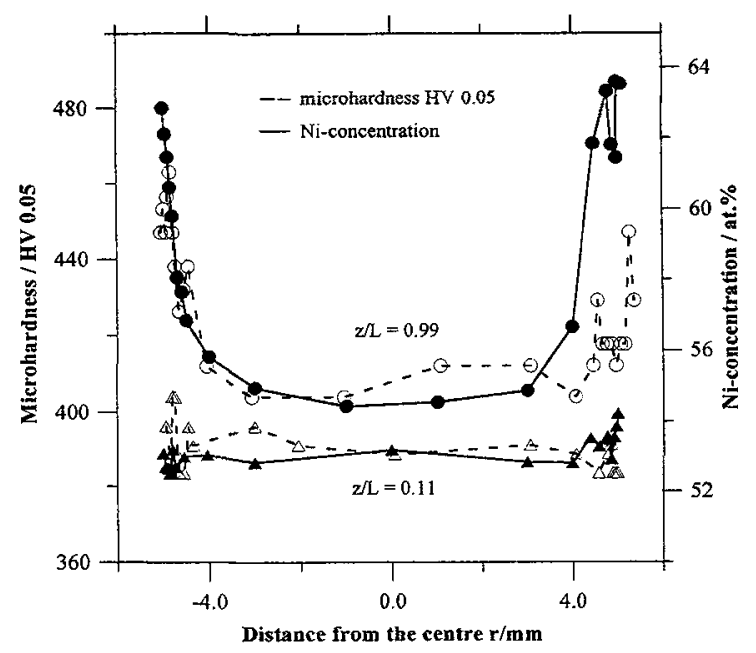

Figure 6: Experimentally determined radial variation of $\mathrm{Ni}$ concentration and microhardness $\mathrm{HVO} 0.05$ in a Bridgman NiAl single crystal of nominal composition $\mathrm{Ni}-47$ at- $\% \mathrm{Al}$ at two cross sections with respect to the length co-ordinate $(z / L=0.11$ and $z / L=0.99)$

Table 2: Schmid factors of the selected orientations for compression tests

\begin{tabular}{|c|c|c|c|}
\hline Compression axis & \multicolumn{3}{|c|}{ Schmid factors of the slip systems } \\
& {$[001](110)$} & {$[010](101)$} & {$[100](011)$} \\
\hline$[111]$ & 0.47 & 0.47 & 0.47 \\
{$[112]$} & 0.47 & 0.35 & 0.35 \\
{$[123]$} & 0.45 & 0.40 & 0.28 \\
\hline
\end{tabular}


Table 3: $\quad$ Room temperature compressive properties of NiAl single crystals $(0.2 \%$ yield strength, critical resolved shear stress CRSS for $<001>\{110\}$ slip systems, and work hardening rate WHR in the plastic strain interval $2 \ldots 3 \%$ )

\begin{tabular}{|c|c|c|c|c|}
\hline Axis orientation & $\begin{array}{c}0.2 \% \text { yield stress } \\
{[\mathrm{MPa}]}\end{array}$ & $\begin{array}{c}\text { CRSS } \\
{[\mathrm{MPa}]}\end{array}$ & $\begin{array}{c}\text { WHR } \\
{[\mathrm{MPa} / \%]}\end{array}$ & Reference \\
\hline$<123>$ & 230.8 & 103.9 & 20.5 & \\
& 233.1 & 105.9 & CP 24.5* & {$[14]$} \\
\hline$<112>$ & 212.6 & 96.5 & HP 13.8* & {$[14]$} \\
\hline$<111>$ & 235 & 108 & HP 13 & \\
\hline
\end{tabular}

*) WHR at $4 \%$ plastic strain

**) WHR at $2 \%$ plastic strain.

HP: high purity (produced by containerless zone melting)

$\mathrm{CP}$ : conventional purity (Bridgman)

As expected, crystals with $<111>$ axis orientation (Fig. 7) show the highest observed work hardening rate resulting from the strong interaction of dislocations of the three active conjugated slip systems with nominal compressive stresses of up to $1400 \mathrm{MPa}$. CRSS and WHR fit well with results of Darolia et al. [15]. In spite of the high stresses large plastic strains of more than $25 \%$ are obtained.

Crystals with $<123>$ axis orientation (Fig. 8) are deformed mainly by single slip up to about $10 \%$ plastic strain thus showing a lower initial work hardening rate. At higher strains an increase in the work hardening rate is observed which is due to the activation of a second slip system. First cracks are initiated at strains between 15 and $20 \%$. The failure of the samples tested in compression appears to be due to radial tensile stresses which are developed by the plastic compressive strain and which cause axial cracks as discussed in $[16,17]$.

The <112>-oriented crystal (Fig. 9) exhibits the lowest work hardening rate of $13 \mathrm{MPa} / \%$ which, however, increases strongly if at high strains above about $18 . . .20 \%$ secondary slip is initiated. Whereas the other compression curves presented in Figs. 7 and 8 are from Bridgman single crystals, the curve in Fig. 9 is measured on a zone refined single crystal. This crystal sustained plastic strains of more than $30 \%$ without cracking (the experiment was discontinued at $31 \%$ strain).

\subsection{Dislocation structure}

TEM examinations on thin foils were conducted to identify the nature of dislocations in specimens compressed at room temperature up to a pre-selected strain. Typical dislocation structures developed in specimens compressed in $<123\rangle$ direction with a plastic strain of $1.8 \%$ are shown in Figure 10 a - c. In Fig. $10 \mathrm{a}$ and $\mathrm{b}$ the foil normal is parallel to the [123] direction and nearly parallel to the [111] direction. In Fig. 10 a using a diffraction vector $\mathbf{g}=(01 \overline{1})$ dislocations with Burgers vector $\mathrm{a}_{0}[001]$ and $\mathrm{a}_{\mathrm{o}}[010]$ are visible. The deformation substructure consists of dislocations arranged in walls and loops, debris and isolated dislocations in the regions between the walls. A Burgers vector analysis with $\mathbf{g}=(1 \overline{\mathrm{T}} 0)$ proved that the dislocations mainly belong to the primary slip system [001] (110) because dislocations with $\mathbf{b}=\mathrm{a}_{\mathrm{o}}[001]$ are invisible or show residual contrast. Only few dislocations with Burgers vectors other than $a_{0}[001]$ are seen. Sections with a foil normal perpendicular to the compression axis having a foil plane near (100) confirmed the results with respect to the Burgers vectors. Loops, debris and long dislocation lines in the foil plane as well as tangles and dislocation walls were detected (see Figure $10 \mathrm{c}$ ). 


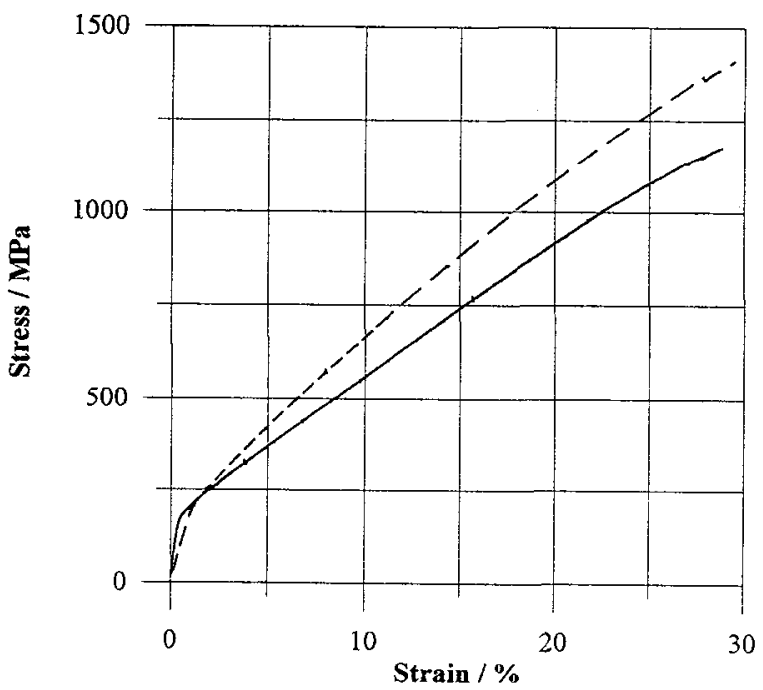

Figure 7: Compressive stress-strain curves of Bridgman single crystals with $<111>$ axis orientation deformed at room temperature with an initial strain rate of $1.7 \cdot 10^{-4} \mathrm{~s}^{-1}$

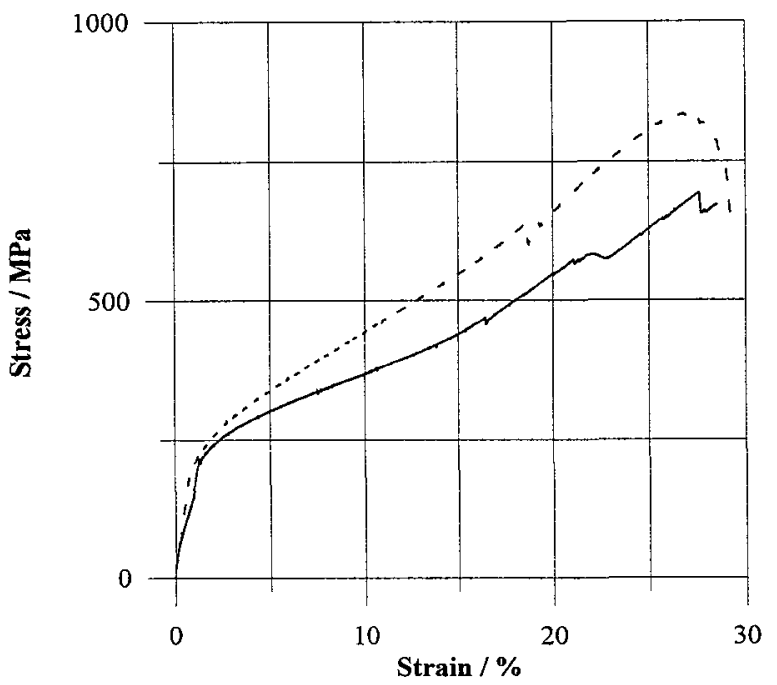

Figure 8: as Figure 7, axis orientation $<123>$ 


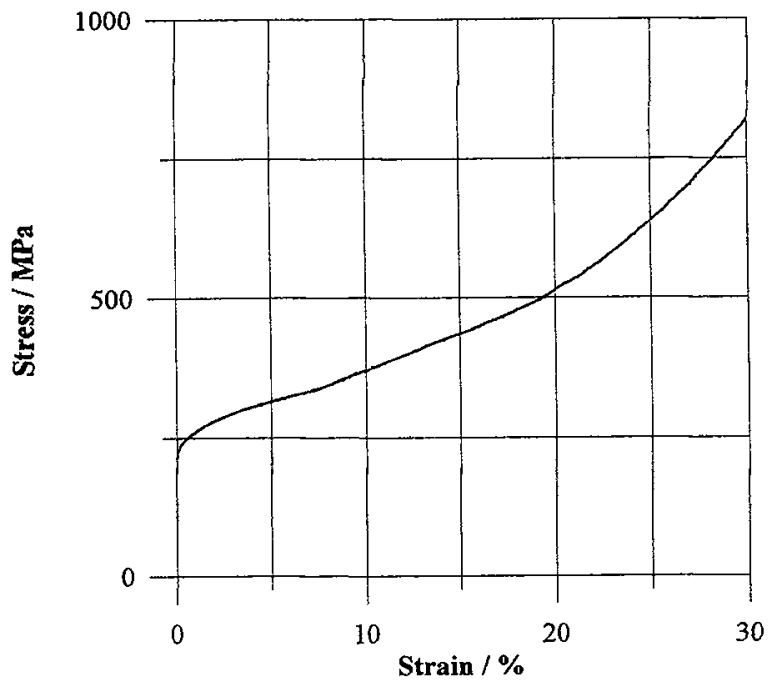

Figure 9: Compressive stress-strain curves of a zone refined single crystal with $\langle 112>$ axis orientation deformed at room temperature with an initial strain rate of $1.7 \cdot 10^{-4} \mathrm{~s}^{-1}$

In specimens with [111] compression axis the three possible $a_{0}<100>$ Burgers vectors could be distinguished. The deformation substructure is characterized mainly by walls with a high dislocation density resulting from the interaction of the three active conjugate slip systems (Figure 11).

\section{CONCLUSIONS}

1. A method has been developed which allows the preparation of intermetallic NiAl single crystals with small or well defined deviation from stoichiometric composition and high purity. The starting material is melted from pure $\mathrm{Al}$ and $\mathrm{Ni}$ in a vacuum induction furnace with a slight surplus of $\mathrm{Al}$. By means of a special vacuum treatment of the melt in the Bridgman apparatus before the crystal growing process commences the melt composition is adjusted by preferential evaporation of Al. The process parameters are fixed on the basis of measurements of the reciprocal residual resistivity ratio.

2. The homogeneity of the single crystals was analyzed by theoretical and experimental investigations on materials with various $\mathrm{Ni}$ and $\mathrm{Al}$ concentrations. Single crystals with low deviation from stoichiometry showed a nearly constant composition over most of their length and significant macrosegregegations of the surplus element only in the last-solidifying part. Crystals with larger deviation from stoichiometry possessed a gradual increase of the concentration of the surplus element with increasing slope as a function of the length co-ordinate. The macro-segregations were considerably more pronounced in the subsurface regions as compared to the crystal axis.

3. The macro-segregations are reflected in corresponding variations of the microhardness in the axial and radial direction.

4. Room temperature compression tests were performed on single crystals in the "soft orientations" $<111>$, $<112>$ and $<123>$ with predicted $<001>\{110\}$ slip. The $0.2 \%$ yield stress, the critical resolved shear stress and the work hardening rate are comparable with results on high purity single crystals reported in the literature. Compressive plastic strains of the order of $\geq 25 \%$ were obtained. It can be concluded that "soft oriented" NiAl single crystals of high purity and small deviations from stoichiometric composition show a sufficiently high formation rate and mobility of dislocations to allow a remarkable room temperature ductility in uni-axial compression (see also $[1-3,17]$ ).

5. Interactions of dislocations from conjugated slip systems and a reduced ability for cross slip lead to a strong work hardening rate which is high from the beginning of plastic strain in the symmetrically oriented $<111>$ crystals but is developed only at higher strains and to a lesser degree in the $\langle 112\rangle-$ and $\langle 123\rangle$ oriented crystals. 


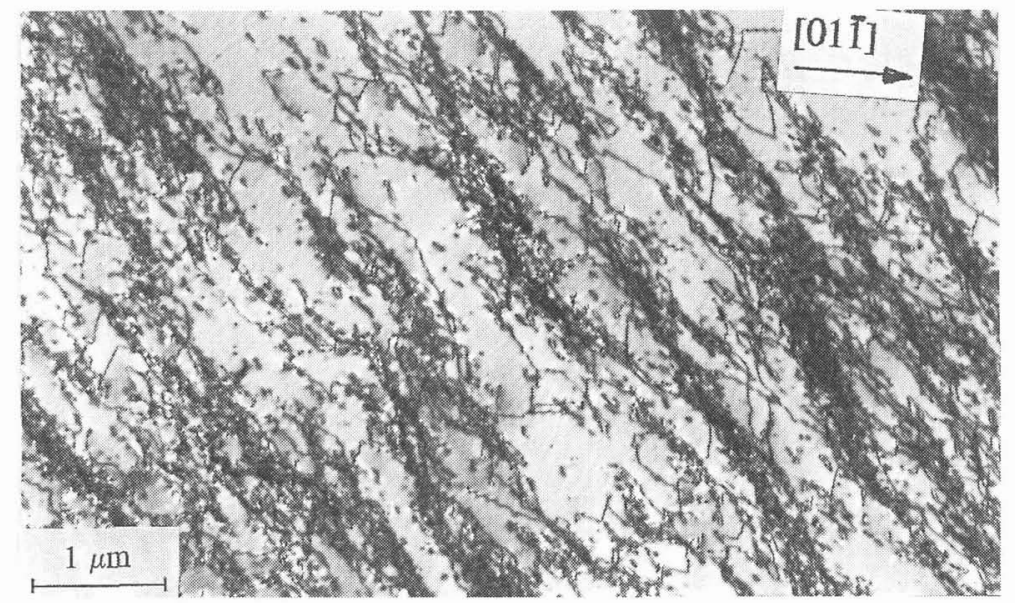

Figure 10 a-c: TEM micrographs of the dislocation structure of a Bridgman crystal compressed in [123] direction up to a plastic strain of $1.8 \%$ at room temperature.

a) Foil plane near (111), $\mathbf{g}=(01 \overline{1}), \mathbf{b}=\mathrm{a}_{0}[001]$ and $\mathrm{a}_{0}[010]$ visible

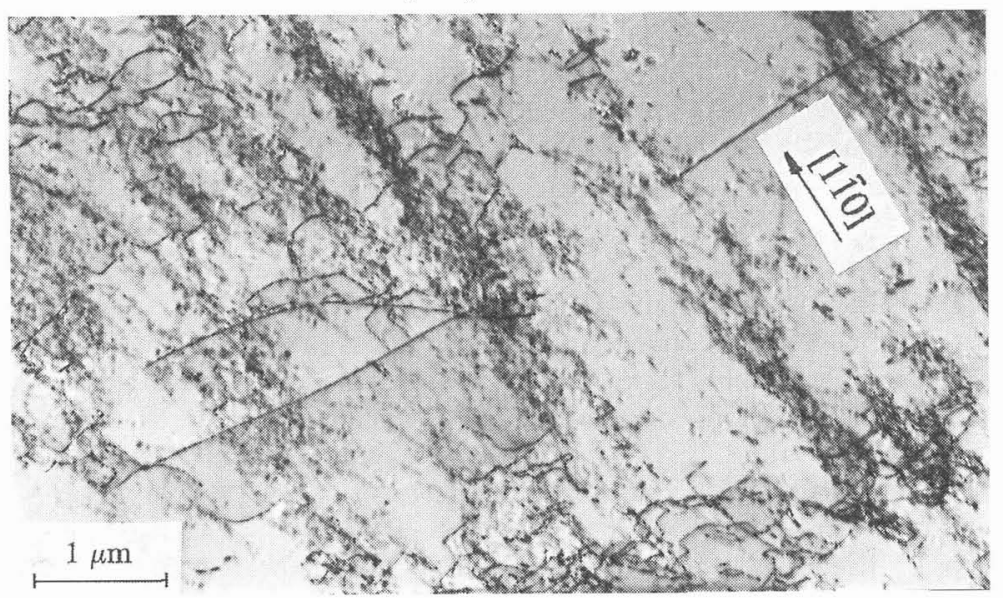

Figure $10 b: \mathbf{g}=(1 \overline{1} 0), \mathbf{b}=a_{0}[001]$ extinguished or residual contrast

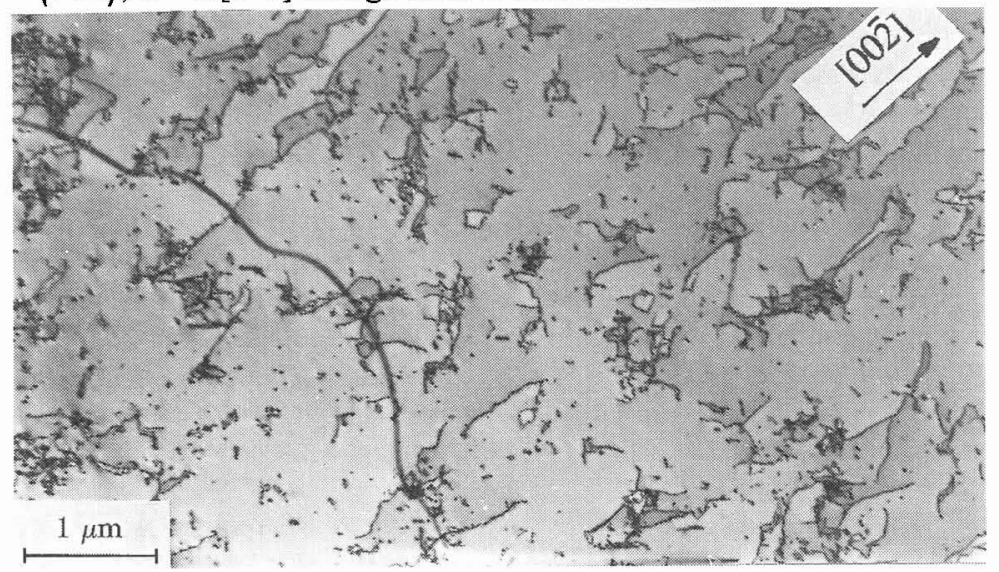

Figure $10 \mathrm{c}$ : Foil plane near $(100), \mathbf{g}=(00 \overline{2})$ 


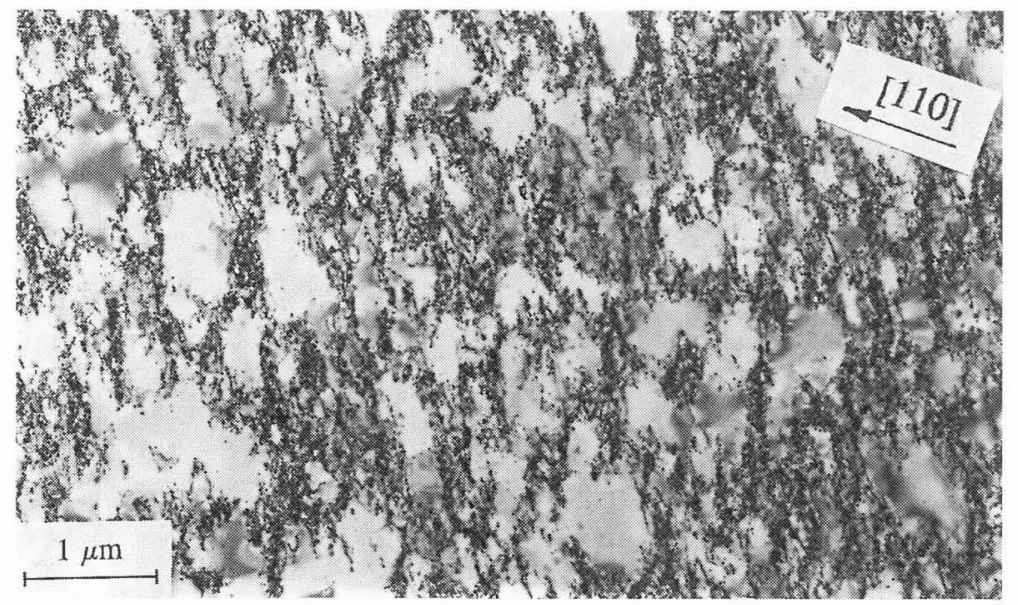

Figure 11: TEM micrograph of the dislocation structure of a Bridgman crystal compressed in [111] direction up to a plastic strain of $10 \%$ at room temperature. Foil plane $(1 \overline{1} 0)$,

$$
\mathbf{g}=(110)
$$

\section{Acknowledgement}

We express our gratitude to the Deutsche Forschungsgemeinschaft for financial support for this work under grant numbers Lo 548/1-2 and Ko 1225/2-1.

\section{References}

[1] Miracle D. B., Acta metall. mater. 41 (1993) 649-684

[2] Noebe R. D., Bowman R. R. and Nathal M. V., Intern. Mater. Reviews 38 (1993) 193- 232

[3] Darolia R., "NiAl for Turbine Airfoil Applications", Structural Intermetallics, Seven Springs Mountain Resort, Champion, Pennsylvania 26-30 September 1993, R. Darolia, J. J.

Lewandowski, C. T. Liu, P. L. Martin, D. B. Miracle and M. V. Nathal Eds. (The Minerals, Metals and Materials Society, Warrendale, Pennsylvania 1993) pp. 495-504

[4] Hilpert P., private communication

[5] Yamaguchi Y., Kiewit D. A., Aoki T. and Britain J. O., J. Appl. Phys. 19 (1968) 231-232

[6] Yamaguchi Y., Aoki T. and Britain J. O., J. Phys. Chem. Solids 31 (1970) 1325-1343

[7] Jacobi H., Vassos B. and Engell H.-J., J. Phys. Chem. Solids 30 (1969) 1261-1271

[8] Hack J. E., Brzeski J. M. and Darolia R., Scripta Metall. Mater. 27 (1992) 1259-1263

[9] Kurz W. and Fisher D. J., Fundamentals of Solidification, (Trans Tech Publications, Aedermannsdorf, Switzerland, 1992)

[10] Wilke K.-Th., Kristallzüchtung, J. Bohm Ed., (Deutscher Verlag der Wissenschaften, Berlin, 1988) 315

[11] Burton J. A., Prim R. C. and Slichter P. W., J. Chem. Phys. 21 (1953) 1987-1991

[12] Vaerst G., Loeser W., Leonhardt M. and Bächer, I., Intermetallics 3 (1995) in press

[13] Vaerst G., Loeser W., Leonhardt M. and Oswald S., submitted to Scripta Metall. Mater.

[14] Weaver M. L., Kaufman M. J. and Noebe R. D., Scripta Metall. Mater. 29 (1993) 1113-11 18

[15] Darolia R., Lahrman D. F. and Field R. D., Scripta Metall. Mater. 26 (1992) 1007-1012

[16] Noebe R. D., Bowman R. R., Kim J. T. and Gibala R., High Temperature Aluminides and Intermetallics, S. H. Wang et al. Eds. (The Minerals and Materials Society, Warrendale, Pennsylvania 1990) pp. 271-300

[17] Noebe R. D., Kim J. T. and Gibala R., "Structure-Property Relationships in Directionally Solidified Single Crystal NiAl", Interdisciplinary Issues in Materials Processing and Manufactoring, S. K. Samanta, R. Kommanduro and R. McMeeking Eds. (ASME, New York 1988), pp. 223-231 